\title{
CÉLULAS SOLARES FINAS EM SILÍCIO TIPO N: AVALIAÇÃO DE DIFERENTES PASTAS METÁLICAS PARA CONTATO ELÉTRICO DA FACE DOPADA COM BORO
}

\author{
Adriano Moehlecke' \\ Rodrigo Carvalho de Campos ' \\ Izete Zanesco'
}

\begin{abstract}
Resumo
O principal objetivo da indústria de células solares é reduzir os custos de produção a fim de que a tecnologia fotovoltaica possa ser competitiva com outras formas de produção de energia elétrica. A combinação do uso de silício tipo n para a obtenção de dispositivos de maior eficiência e lâminas finas podem ser alternativas para a redução dos custos. Este trabalho tem por objetivo apresentar a análise de diferentes pastas metálicas para formar a malha de contato elétrico da face dopada com boro em células solares fabricadas sobre lâminas finas de silício monocristalino Czochralski, grau solar, tipo $n$. Foram estudadas as estruturas $\mathrm{p}^{+} \mathrm{nn}^{+}$e $\mathrm{n}^{+} n \mathrm{p}^{+}$. Comparando-se pastas de $\mathrm{Ag}, \mathrm{Ag} / \mathrm{Al}$ e Al, concluiu-se que a última permitiu a produção dos dispositivos mais eficientes. Observou-se que esta pasta deve ser depositada antes do filme dielétrico de $\mathrm{TiO}_{2}$ porque não perfura o filme no processo térmico de queima de pastas. Com a pasta de aluminio, as células solares com estrutura $n^{+} \mathrm{np}^{+}$e $\mathrm{p}^{+} \mathrm{nn}^{+}$atingiram eficiências de 13,4\% e 12,6\%, respectivamente, valores relativamente baixos devido ao uso de lâminas finas de silício grau solar e a ausência de passivação de superfícies.
\end{abstract}

Palavras-chave: Células solares; Silício tipo n; Lâminas finas.

\section{THIN N-TYPE SILICON SOLAR CELLS: EVALUATION OF DIFFERENT METAL PASTES TO THE ELECTRICAL CONTACT OF THE BORON DOPED FACE}

\begin{abstract}
The main goal of the solar cell industry is to reduce the production cost so that the photovoltaic technology can be competitive with other kinds of electricity generation. The combination of the use of $n$-type silicon to obtain higher efficiency devices and thinner wafers can be an alternative for reducing cost. The aim of this work is to present the analysis of different metal pastes to form the electrical contact grid of the boron doped face in solar cells fabricated in thin wafers of $\mathrm{n}$-type Czochralski-growth solar grade silicon. The $\mathrm{p}^{+} \mathrm{nn}^{+}$and $\mathrm{n}^{+} \mathrm{np}^{+}$structures were studied. By comparing metal pastes of $\mathrm{Ag}, \mathrm{Ag} / \mathrm{Al}$ and $\mathrm{Al}$, we concluded that the latter enabled the manufacture of the more efficient solar cells. The aluminum metal paste has to be screen-printed before the deposition of the dielectric film of $\mathrm{TiO}_{2}$ because it does not etch-through the thin film during firing of metal pastes. By using aluminum paste deposited on the boron doped face, the solar cells with $\mathrm{n}^{+} n \mathrm{p}^{+}$and $\mathrm{p}^{+} \mathrm{nn}^{+}$structures reached efficiencies of $13.4 \%$ and $12.6 \%$, respectively, values relatively low due to the use of thin solar grade silicon wafers and the absence of surface passivation.
\end{abstract}

Keywords: Solar cells; N-type silicon; Thin wafers.

\section{INTRODUÇÃO}

No custo de produção de módulos fotovoltaicos, a lâmina de silício representa da ordem de $50 \%$ do valor final [I]. Para diminuir esses custos vem sendo proposto e estudado o uso de silício de menor qualidade e a redução das espessuras atuais de $200 \mu \mathrm{m}$ para $120 \mu \mathrm{m}$ [I-4].
No entanto, para que ambos os métodos sejam realmente efetivos na redução de custos, os processos de fabricação deverão resultar em células de eficiência similar as atuais, que são da ordem de $15 \%$ a $16 \%$. Além disto, outro aspecto importante a ser considerado é a eficiência de produção,

'Núcleo de Tecnologia em Energia Solar, Programa de Pós-graduação em Engenharia e Tecnologia de Materiais, Faculdade de Física, Pontifícia Universidade Católica do Rio Grande do Sul - PUCRS, Porto Alegre, RS, Brasil. E-mail: moehleck@pucrs.br

2176-1523 (C) 2016 Associação Brasileira de Metalurgia, Materiais e Mineração. Publicado pela ABM. Este é um artigo de acesso aberto distribuído sob os termos da licença Creative Commons CC BY-NC-ND (Attribution-NonCommercial-NoDerivs) - https:// creativecommons.org/licenses/by-nc-nd/4.0\%. 
que deve ficar acima de $90 \%$ para ser compatível com a produção atual [5].

Em 20II, 84\% da produção mundial de células solares utilizou lâminas de silício cristalino tipo $\mathrm{p}$ dopadas com boro e em somente 3,9\% foram usadas lâminas tipo n dopadas com fósforo [6]. A dopagem do substrato com boro foi estabelecida como padrão nos anos 60 , como resultado do uso inicial das células solares para aplicações espaciais. Naquela época, as células com base $p$, dopadas com boro, eram usadas porque possuíam uma maior tolerância ao impacto de partículas existentes no espaço do que as estruturas com base $n$ [7]. Nos anos de 1970, após a crise do petróleo, as células solares começaram a ser usadas em aplicações terrestres e o silício tipo $\mathrm{p}$ continuou a ser o padrão utilizado pela indústria. No entanto, demonstrou-se na última década que a dopagem com boro em todo o substrato pode produzir problemas de degradação da eficiência das células solares de uso terrestre, principalmente para lâminas normalmente usadas na indústria, que possuem resistividade da ordem de I $\Omega . c m[8,9]$. Esta degradação é devida à interação entre os átomos de oxigênio presentes nas lâminas de silício cristalino $\mathrm{Cz}$ (Czochralski) com os átomos de boro, sendo que a radiação solar transforma os defeitos boro-oxigênio em centros de recombinação efetivos.

As células solares em base $\mathrm{n}$ podem ter duas estruturas básicas:

I) a estrutura $\mathrm{p}^{+} \mathrm{nn}^{+}$, com emissor frontal dopado com boro e região de BSF (back surface field) dopada com fósforo;

2) a estrutura $n^{+} n p^{+}$, com uma região de campo retrodifusor na face frontal, denominada de FSF (front surface field) e o emissor $\mathrm{p}^{+}$na face posterior, que pode ser dopado com boro ou alumínio.

A primeira tem a vantagem de ter a junção pn próxima da face frontal e depender relativamente menos da recombinação na base, podendo-se usar lâminas de baixa resistividade [10]. Por outro lado, a região $\mathrm{p}^{+}$é difícil de passivar com $\mathrm{SiO}_{2}$ ou $\mathrm{SiNx}$ e deste modo, há alta recombinação em superfície. $\mathrm{Na}$ segunda estrutura, a superfície frontal é dopada com fósforo, sendo possível a obtenção de passivação de superfície mais eficiente, mas o substrato $\mathrm{n}$ deverá ter um elevado tempo de vida dos portadores de carga minoritários para permitir que os portadores gerados alcancem a junção pn na face posterior $[11,12]$.

$\mathrm{Na}$ fabricação de células solares, no processo de metalização são estabelecidos os contatos elétricos sobre a região $\mathrm{n}^{+}$, dopada com fósforo e $\mathrm{p}^{+}$, dopada com boro ou alumínio. A estrutura padrão atual nas indústrias de células solares é a $\mathrm{n}^{+} \mathrm{pp}^{+}$, com difusão de fósforo e alumínio, e metalização em ambas as faces usando a serigrafia. $\mathrm{Na}$ face frontal são usadas pastas de prata depositadas em forma de malha e na posterior uma pasta de alumínio é depositada em toda a superfície. A pasta de alumínio, além do contato metálico, tem a função de produzir uma região de campo retrodifusor (BSF), isto é, região que repele portadores de carga minoritários, diminuindo a recombinação em superfície [7]. No entanto, em lâminas finas, a pasta de alumínio não pode ser usada desta forma porque se produz o efeito de abaulamento durante o processo térmico de queima (firing) das pastas de serigrafia [3]. O abaulamento é resultado dos diferentes coeficientes de expansão do silício e da região com pasta de alumínio.

O objetivo deste trabalho é apresentar a análise da influência das pastas de metalização depositadas sobre a face dopada com boro $\left(\mathrm{p}^{+}\right)$de células solares $\mathrm{p}^{+} \mathrm{nn}^{+} \mathrm{e}$ $\mathrm{n}^{+} \mathrm{np}^{+}$fabricadas em lâminas finas, da ordem de I $40 \mu \mathrm{m}$ de espessura, de silício $\mathrm{Cz}$ grau solar tipo n. Foram fabricadas células solares e comparadas suas características elétricas.

\section{MATERIAIS E MÉTODOS}

A Figura I mostra um esquema do processo de fabricação de células solares finas, com estrutura $n^{+} n p^{+} e^{+} n n^{+}$. O processo é o mesmo para ambas as estruturas, modificando-se o modo de iluminação, ou seja, pela face $n^{+}\left(n^{+} n p^{+}\right)$ou face $\mathrm{p}^{+}\left(\right.$para a $\left.\mathrm{p}^{+} \mathrm{nn}^{+}\right)$.

As lâminas encontradas no mercado, em geral, têm espessuras maiores que as necessárias para realização deste trabalho, sendo da ordem de $200 \mu \mathrm{m}$. Sendo assim, para trabalhar com lâminas com espessuras entre I $35 \mu \mathrm{m}$ e I $40 \mu \mathrm{m}$, foi necessária a realização de um afinamento nas lâminas (etapa I na Figura I). As lâminas usadas neste trabalho foram de silício monocristalino grau solar, crescido pela técnica $\mathrm{Cz}$, tipo $\mathrm{n}$, dopadas com fósforo, com resistividade de I-20 $\Omega . c m$, orientação dos planos cristalográficos $\{100\}$, com $100 \mathrm{~mm}$ de diâmetro e $200 \mu \mathrm{m}$ de espessura. $O$ processo de afinamento executado tem como base o ataque químico composto por hidróxido de potássio e água deionizada $\left(\mathrm{H}_{2} \mathrm{O}_{\mathrm{DI}}\right)$ e foi desenvolvido por Osório [13] e Osório et al. [14], controlando-se o tempo de processo para ajustar a espessura final.

Para que as células fotovoltaicas tenham uma eficiência otimizada, faz-se necessário que o máximo de radiação solar seja absorvida. Para tal, a refletância da célula deve ser diminuída. Uma maneira de reduzir a refletância é efetuando um processo chamado de texturação por intermédio de um ataque químico anisotrópico que produz micropirâmides na superfície da lâmina. Este processo (etapa 2 na Figura I) foi realizado utilizando uma solução composta de hidróxido de potássio, álcool isopropílico e água deionizada [13]. Após o ataque químico anisotrópico, as lâminas foram limpas com a limpeza RCA composta de $\mathrm{HCl}: \mathrm{H}_{2} \mathrm{O}_{2}: \mathrm{H}_{2} \mathrm{O}_{\mathrm{DI}}(\mathrm{I}: 1: 5)$ [15].

A formação de uma junção pn possibilita o funcionamento de uma célula solar de silício. No caso de uma célula produzida com silício de tipo n, essa junção pode ser produzida com a difusão térmica de boro. A técnica usada para a deposição do boro foi a do spin-on. Nesta, a lâmina é mantida, por vácuo, em uma base giratória de alta rotação e um líquido contendo o dopante (PBF20, da empresa 


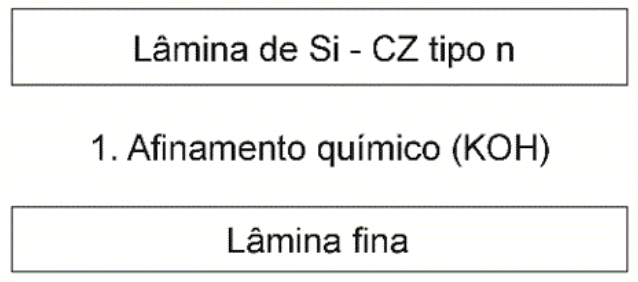

2. Texturação e limpeza química

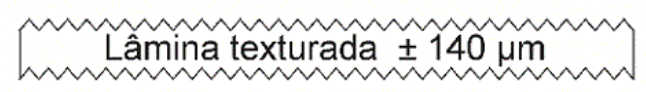

3. Deposição, difusão de boro e oxidação

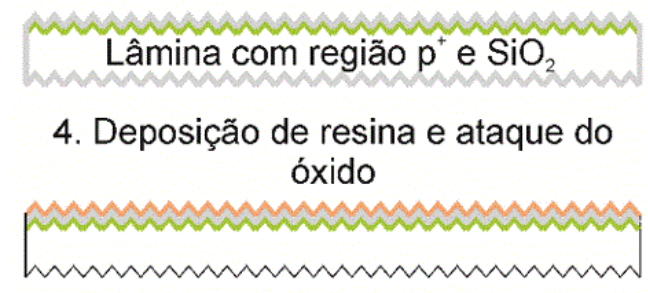

5. Retirada da resina e limpeza química Região p protegida por SiO
6. Difusão de fósforo, ataque dos óxidos e limpeza

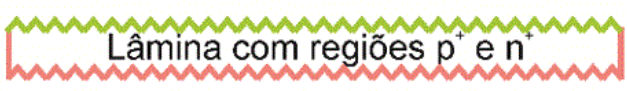

7. Deposição de filme AR $\left(\mathrm{TiO}_{2}\right)$

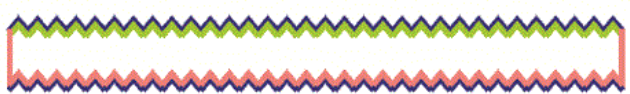

8. Metalização por serigrafia e queima das pastas

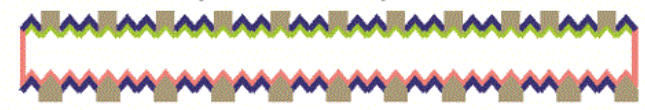

9. Corte com laser

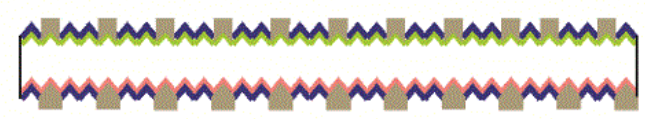

Figura I. Processo de fabricação de células solares em lâminas de silício tipo n.

Filmtronics) é vertido sobre a lâmina, formando-se um filme sobre sua superfície. Para finalizar o processo de deposição do boro (etapa 3 na Figura I), as lâminas foram introduzidas em uma estufa para secagem e evaporação do solvente. Após a deposição de boro na lâmina, efetuou-se o processo de difusão térmica do boro em forno elétrico com tubo de quartzo. $\mathrm{O}$ boro foi difundido a $975^{\circ} \mathrm{C}$ seguido de uma oxidação a $1000^{\circ} \mathrm{C}$ por $20 \mathrm{~min}$, processo otimizado em trabalhos anteriores realizados no Núcleo de Tecnologia em Energia Solar da PUCRS [16-19]. A região $\mathrm{p}^{+}$dopada com boro foi caracterizada pela medida da resistência de folha $(\mathrm{R} \square)$. A resistência de folha consiste em uma medida da resistividade média ao longo da espessura de uma dada região com átomos difundidos.

Para formação da região $\mathrm{n}^{+}$nas células solares, foi utilizada a técnica da difusão de fósforo em tubo de quartzo com $\mathrm{POCl}_{3}$ como fonte de dopante. No entanto, para que essa técnica seja empregada e seja difundido fósforo em apenas uma das faces da lâmina, é preciso que se proteja a outra face. $O$ óxido formado na lâmina no passo de difusão de boro é uma eficiente proteção contra a subsequente difusão de fósforo $[16,20]$, mas como ele recobre toda a lâmina, deve ser retirado da face na qual se deseja difundir fósforo. Assim, na etapa 4, depositou-se uma resina por spin-on na face dopada com boro e a resina foi secada em uma estufa. Após esse processo, a lâmina foi imersa em uma solução de $\mathrm{HF}$ tampão que removeu a camada de $\mathrm{SiO}_{2}$ na face sem resina. Esta foi removida das lâminas mediante a imersão em acetona, álcool isopropílico e água deionizada (etapa 5). Assim, as lâminas permaneceram com óxido na face previamente dopada com boro e sem óxido na face que receberá o fósforo. Por último, realizaram-se as limpezas químicas RCA [15] para retirar resíduos de resina, outros materiais orgânicos e qualquer outro contaminante para que estes não sejam difundidos na lâmina no próximo passo térmico.

$\mathrm{Na}$ difusão térmica de fósforo a partir de $\mathrm{POCl}_{3}$ (etapa 6), o dopante deve ser introduzido no ambiente do forno de difusão e reagir com $\mathrm{O}_{2}$ para formar $\circ \mathrm{P}_{2} \mathrm{O}_{5}$, que se deposita na lâmina de silício e é a fonte de dopante durante o processo térmico. O fósforo foi difundido no intervalo de temperaturas de $855^{\circ} \mathrm{Ca} 875^{\circ} \mathrm{C}$, para formar uma região $\mathrm{n}^{+}$com resistência de folha da ordem de $30-40 \Omega / \square$, parâmetros otimizados no âmbito do projeto FINEP "Desenvolvimento de células solares eficientes em lâminas de silício tipo n" [19].

Na difusão de fósforo, formou-se sobre a superfície da lâmina de silício uma camada de silicato de fósforo que deve ser eliminada na sequência do processo, pois essa camada cria uma zona de alta recombinação e ao mesmo tempo dificulta o estabelecimento do contato metal-semicondutor durante 
- processo de queima das pastas metálicas de serigrafia. O silicato de fósforo foi extraído com ácido fluorídrico e as lâminas foram limpas com água deionizada e com uma solução de limpeza RCA. Em seguida foram novamente limpas com água deionizada e logo secadas com $\mathrm{N}_{2}$.

A fim de reduzir ainda mais a reflexão da radiação solar, depositou-se sobre as lâminas de silício um filme antirreflexo (AR), que na Figura I é a etapa 7. O filme de dióxido de titânio é uma opção muito vantajosa, pois não é tóxico, tem alta resistência química, tem um alto índice de refração e um baixo índice de absorção [2I]. O filme AR foi depositado por evaporação em alto vácuo com canhão de elétrons. Na técnica de deposição por evaporação, um feixe de elétrons de $10 \mathrm{keV}$ bombardeia o material a ser evaporado, sendo esse feixe extraído de um cátodo e direcionado por um campo magnético. $O$ material é colocado em um cadinho resfriado, sendo que apenas o material é fundido devido ao fato de o feixe de elétrons ser focalizado de maneira controlada sobre $\circ$ alvo. Em relação à etapa de deposição do filme, verificou-se se deve ser depositado antes ou depois da metalização da face $\mathrm{p}^{+}$.

Para que uma célula solar seja efetiva na produção de energia é necessário que os portadores de carga fotogerados sejam coletados e possam circular com baixa resistência para um circuito externo. Para tal, devem-se imprimir trilhas metálicas por onde a corrente elétrica possa fluir com a menor resistência elétrica possível. No entanto, as trilhas devem ocupar uma menor área possível para evitar ao máximo a reflexão da radiação incidente. Dentre os métodos de formação dessas trilhas metálicas, se destaca a serigrafia em células solares industriais, por apresentar um custo baixo em relação a outros métodos e ser um processo rápido e eficiente [22]. Sobre a região $\mathrm{n}^{+}$foi usada a pasta de prata PVI7A da empresa DuPont. Depois da deposição, a pasta foi secada em forno de esteira. Para a face $\mathrm{P}^{+}$, foram testadas três pastas metálicas: PVI7A, PV38I e PV202, todas da Dupont. $A$ pasta $\mathrm{PV} 38 \mathrm{I}$ é composta de $\mathrm{Al}$ e normalmente é usada para formar regiões de BSF em células solares $\mathrm{n}^{+} \mathrm{Pp}^{+}$. A pasta PV202 é composta de Ag e Al, possui maior condutividade elétrica que a de $\mathrm{Al}$ e pode ser soldada com as típicas fitas de cobre-estanho-prata usadas para conectar células solares. Depois da deposição, a pasta de $\mathrm{Al}$ ou $\mathrm{Ag} / \mathrm{Al}$ passou pelo processo de secagem em forno de esteira e em seguida, as lâminas foram submetidas a um processo térmico de alta temperatura em forno de esteira para estabelecer o contato elétrico com a lâmina de silício. Este último processo comumente é chamado de queima das pastas (firing), quando as pastas devem perfurar (etch-through) o filme antirreflexo. Foram usadas duas temperaturas de queima $\left(T_{\text {Queima }}\right): 840^{\circ} \mathrm{C}$ e $900^{\circ} \mathrm{C}$. O primeiro valor foi encontrado como ótimo em trabalhos anteriores em lâminas finas de silício Cz tipo $p$ [13] e o segundo foi testado como limite superior para produzir a perfuração do filme antirreflexo pelas pastas de Al. O processo de metalização foi resumido na etapa 8 da Figura $I$.
Para finalizar, na etapa 9, as bordas das células solares foram cortadas por meio de um sistema com radiação laser para obter células solares pseudo-quadradas de $80 \mathrm{~mm} \times 80 \mathrm{~mm}$, com área de $61,58 \mathrm{~cm}^{2}$.

Foram fabricadas células solares para analisar as pastas metálicas. Primeiramente, comparam-se as pastas de $\mathrm{Al} / \mathrm{Ag}$ e de Al e depois, as pastas de Al e de Ag. Neste segundo, analisou-se o efeito da ordem de deposição do filme de $\mathrm{TiO}_{2}$, isto é, antes ou depois do processo térmico de queima das pastas de metalização.

Os dispositivos foram caracterizados sob condições padrão $\left(100 \mathrm{~mW} / \mathrm{cm}^{2}\right.$, espectro $A M I, 5 \mathrm{G}$ e $\left.25^{\circ} \mathrm{C}\right)$ em um simulador solar classe AAA calibrado com células solares de silício previamente medidas no CalLab - FhG-ISE (Fraunhofer-Institut für Solare Energiesysteme), Alemanha. A partir da curva J-V (densidade de corrente elétrica-tensão elétrica), foram obtidos os parâmetros elétricos característicos das células solares: I) densidade de corrente de curto-circuito $\left(U_{S C}\right)$; 2$)$ tensão de circuito aberto $\left.\left(V_{o c}\right) ; 3\right)$ fator de forma $(F F)$ e eficiência de conversão de energia $(\eta)$.

\section{RESULTADOS E DISCUSSÃO}

A Tabela I mostra os parâmetros elétricos médios das células solares e a Tabela 2 resume as características elétricas dos dispositivos mais eficientes. Foram testadas as pastas de $\mathrm{Ag} / \mathrm{Al}$ e Al para formação da malha de metalização da face dopada com boro $\left(\mathrm{p}^{+}\right)$. As regiões $\mathrm{n}^{+}$e $\mathrm{p}^{+}$apresentaram resistências de folha médias (média de 13 pontos distribuídos na face da lâmina) de $(39 \pm 2) \Omega / \square$ e de $(33 \pm 2) \Omega / \square$, respectivamente. Não foi depositado filme AR na face $\mathrm{p}^{+}$a fim de serem evitados os possíveis problemas relativos à perfuração do filme pelas pastas. Usou-se a temperatura de queima de pastas $\left(\mathrm{T}_{\text {Queima }}\right)$ de $840^{\circ} \mathrm{C}$, valor que produziu as células solares finas mais eficientes em lâminas de silício Cz tipo p no trabalho de Osório [13].

Como se pode verificar, a pasta PV38I produziu as células solares mais eficientes, destacando-se a maior tensão de circuito aberto, resultado da obtenção de uma região $\mathrm{p}^{+}$seletiva, isto é, uma região dopada com boro entre as trilhas metálicas e uma região dopada com boro e alumínio sob a malha metálica. A produção de uma região $\mathrm{p}^{+}$espessa de $\mathrm{Al}$ reduz a recombinação de portadores de carga minoritários nesta região. $\mathrm{A} \mathrm{J}_{\mathrm{SC}}$ relativamente baixa apresentada pelas células solares com estrutura $\mathrm{p}^{+} \mathrm{nn}^{+}$é devida principalmente à ausência de filme AR.

Com a constatação de que a pasta PV38I resultava em células solares mais eficientes, tanto em dispositivos $\mathrm{p}^{+} \mathrm{nn}^{+}$ como $n^{+} n p^{+}$, realizou-se uma análise da ordem de deposição do filme $A R$ na face $\mathrm{p}^{+}$dos dispositivos. Para tal, em um grupo de células solares, o filme $\mathrm{AR}$ de $\mathrm{TiO}_{2}$ foi depositado antes da metalização, sendo que durante o processo térmico de queima das pastas, a pasta de Al, PV38I, deve perfurar o filme. No outro conjunto de células solares, primeiro se depositou a pasta PV38I por serigrafia na face $\mathrm{p}^{+}$e depois 
o filme AR foi depositado. Deste modo, a pasta de Al não necessita perfurar o filme AR. Para controle do processo de perfuração, foram fabricados dispositivos com a pasta PVI7A sobre a face $\mathrm{p}^{+}$, embora não seja adequada para este tipo de dopagem, mas eficiente na perfuração de filmes AR para estabelecimento de contato elétrico com a lâmina de silício.

Foram fabricadas células solares usando as difusões de boro e fósforo otimizadas nas referências de Zanesco e Moehlecke $[18,19]$ : difusão de boro a $975^{\circ} \mathrm{C}$ e difusão de fósforo a $855^{\circ} \mathrm{C}$. As regiões $\mathrm{n}^{+}$e $\mathrm{p}^{+}$apresentaram resistência de folha média de $(54 \pm 2) \Omega / \square$ e de $(54 \pm 3) \Omega / \square$, respectivamente. Depositou-se um filme de $\mathrm{TiO}_{2}$ com $70 \mathrm{~nm}$ de espessura. As pastas foram queimadas na temperatura de $900^{\circ} \mathrm{C}$ para que a pasta de Al pudesse perfurar o filme AR.

Os parâmetros elétricos médios das células solares fabricadas são mostrados na Tabela 3 e os parâmetros dos dispositivos mais eficientes estão na Tabela 4.

Em células solares com o filme AR depositado antes da pasta PV38I, o FF alcançou valor médio de 0,42 e máximo de 0,46 , valores baixos devidos a uma resistência em série elevada, da ordem de $100 \mathrm{~m} \Omega-180 \mathrm{~m} \Omega$, ou resistência série específica de $6,2 \Omega . \mathrm{cm}^{2}-1$ I $\Omega . \mathrm{cm}^{2}$. Na célula solar com FF de 0,768 na Tabela 4, a resistência em série específica foi da ordem de I $\Omega . \mathrm{cm}^{2}$. A partir da análise dos valores de fator de forma, constatou-se que a pasta PV38I, mesmo em temperatura relativamente elevada para o processo de queima de pastas em lâminas finas, não conseguiu perfurar adequadamente o filme de $\mathrm{TiO}_{2}$ para estabelecer um contato elétrico de baixa resistividade. A pasta PVI7A perfurou o filme $A R$, como se pode observar pelos valores maiores de $\mathrm{FF}$, mas não produziu região seletiva tipo $\mathrm{p}^{+} \mathrm{e} \mathrm{V}_{\mathrm{OC}}$ alcançada pelas células solares foi menor que a obtida com a pasta PV38I, mesmo quando esta pasta foi depositada depois do filme de $\mathrm{TiO}_{2}$. Em resumo, para produzir células solares eficientes tipo n com a pasta PV38I, a mesma deve ser depositada sobre a face $\mathrm{p}^{+}$e queimada antes do processo de deposição do $\mathrm{TiO}_{2}$ nesta mesma face.

Tabela I. Características elétricas médias de células solares $n^{+} n p^{+}$e $p^{+} n n^{+}$com pasta PV38I e PV202 para metalizar a face $p^{+}$. Não foi depositado filme AR na face $\mathrm{p}^{+}$. A queima das pastas foi realizada a $840^{\circ} \mathrm{C}$

\begin{tabular}{ccccccc}
\hline Estrutura & Pasta na face $\mathbf{p}^{+}$ & $\mathbf{N}^{\circ}$ de células & Voc $(\mathbf{m V})$ & Jsc $\left(\mathbf{m A} / \mathbf{c m}^{2}\right)$ & FF & $\eta(\%)$ \\
\hline \multirow{2}{*}{$\mathbf{n}^{+} \mathbf{n p}^{+}$} & PV38I & 06 & $582 \pm 8$ & $29,0 \pm 1,5$ & $0,74 \pm 0,02$ & $12,2 \pm 0,9$ \\
\cline { 2 - 8 } & PV202 & 04 & $576 \pm 4$ & $29,6 \pm 0,6$ & $0,68 \pm 0,08$ & $1 \mathrm{I}, 4 \pm 1,2$ \\
\hline \multirow{2}{*}{$\mathbf{p}^{+} \mathbf{n n}^{+}$} & PV38I & 06 & $578 \pm 5$ & $24,7 \pm 0,4$ & $0,74 \pm 0,03$ & $10,3 \pm 0,8$ \\
\cline { 2 - 8 } & PV202 & 04 & $571 \pm 8$ & $25 \pm 2$ & $0,67 \pm 0,08$ & $9,4 \pm 0,8$ \\
\hline
\end{tabular}

Tabela 2. Características elétricas das células solares $n^{+} n p^{+}$e $p^{+} n n^{+}$mais eficientes com pasta PV38I e PV202. Não foi depositado filme AR na face $\mathrm{p}^{+}$. A queima das pastas foi realizada a $840^{\circ} \mathrm{C}$

\begin{tabular}{|c|c|c|c|c|c|}
\hline Estrutura & Pasta na face $p^{+}$ & Voc $(\mathrm{mV})$ & $\mathrm{Jsc}\left(\mathrm{mA} / \mathrm{cm}^{2}\right)$ & $\mathbf{F F}$ & $\eta(\%)$ \\
\hline \multirow{2}{*}{$\mathbf{n}^{+} \mathbf{n p}{ }^{+}$} & PV38I & 589,4 & 30,5 & 0,763 & 13,4 \\
\hline & PV202 & 581,1 & 30,4 & 0,713 & 12,4 \\
\hline \multirow{2}{*}{$\mathbf{p}^{+} \mathbf{n n}^{+}$} & PV38I & 580,0 & 25,4 & 0,768 & $\mathrm{II}, \mathrm{I}$ \\
\hline & PV202 & 577,4 & 26,3 & 0,705 & 10,4 \\
\hline
\end{tabular}

Tabela 3. Características elétricas médias das células solares $n^{+} n p^{+}$e $p^{+} n n^{+}$com pasta PV38I e PVI7A na face $p^{+}$, com diferentes ordens de deposição: antes ou depois do filme de $\mathrm{TiO}_{2}$. A queima das pastas foi realizada a $900^{\circ} \mathrm{C}$

\begin{tabular}{|c|c|c|c|c|c|c|}
\hline Estrutura & Pasta na face $\mathrm{p}^{+}$ & $\mathbf{N}^{\circ}$ de células & Voc (mV) & Jsc $\left(\mathrm{mA} / \mathrm{cm}^{2}\right)$ & $\mathbf{F F}$ & $\eta(\%)$ \\
\hline \multirow{3}{*}{$\mathbf{n}^{+} \mathbf{n p}+$} & PV38I, depois do filme AR & 02 & $579 \pm 1$ & $27 \pm 3$ & $0,42 \pm 0,05$ & $6,6 \pm 1,6$ \\
\hline & PV38I, antes do filme AR & 04 & $584 \pm 1$ & $29,7 \pm 0,9$ & $0,76 \pm 0,0 \mathrm{I}$ & $12,8 \pm 0,4$ \\
\hline & PVI7A, depois do filme AR & 03 & $568 \pm 2$ & $29,9 \pm 0,7$ & $0,70 \pm 0,01$ & $11,73 \pm 0,05$ \\
\hline \multirow{3}{*}{$\mathbf{p}^{+} \mathbf{n n}^{+}$} & PV38I, depois do filme AR & 02 & $579 \pm 2$ & $26 \pm 3$ & $0,42 \pm 0,05$ & $6,2 \pm 1,5$ \\
\hline & PV38I, antes do filme AR & 04 & $584,3 \pm 0,7$ & $29,0 \pm 0,5$ & $0,75 \pm 0,0 \mathrm{I}$ & $12,4 \pm 0,4$ \\
\hline & PVI7A, depois do filme AR & 03 & $569 \pm 2$ & $30,5 \pm 0,5$ & $0,69 \pm 0,01$ & $11,6 \pm 0,2$ \\
\hline
\end{tabular}

Tabela 4. Características das células solares $n^{+} n p^{+}$e $p^{+} n n^{+}$mais eficientes com pasta PV38I e PVI IA na face $\mathrm{p}^{+}$, com diferentes ordens de deposição: antes ou depois do filme de $\mathrm{TiO}_{2}$. A queima das pastas foi realizada a $900^{\circ} \mathrm{C}$

\begin{tabular}{|c|c|c|c|c|c|}
\hline Estrutura & Pasta na face $\mathbf{p}^{+}$ & Voc $(\mathrm{mV})$ & $\mathrm{Jsc}\left(\mathrm{mA} / \mathrm{cm}^{2}\right)$ & $\mathbf{F F}$ & $\eta(\%)$ \\
\hline \multirow{3}{*}{$\mathbf{n}^{+} n \mathbf{p}^{+}$} & PV38I, depois do filme AR & 579,6 & 29,4 & 0,462 & 7,7 \\
\hline & PV38I, antes do filme AR & 585,5 & 30,6 & 0,768 & 13,2 \\
\hline & PVI7A, depois do filme AR & 570,8 & 29,5 & 0,712 & 11,8 \\
\hline \multirow{3}{*}{$\mathbf{p}^{+} \mathbf{n n}^{+}$} & PV38I, depois do filme AR & 580,0 & 28,5 & 0,455 & 7,3 \\
\hline & PV38I, antes do filme AR & 584,1 & 29,2 & 0,747 & 12,6 \\
\hline & PVI7A, depois do filme AR & 569,0 & 30,9 & 0,700 & 11,8 \\
\hline
\end{tabular}


O maior valor de eficiência, de 13,4\% para o caso da estrutura $n^{+} n p^{+}$, foi próximo do obtido com células solares finas em base $\mathrm{p}$, com estrutura $\mathrm{n}^{+} \mathrm{pp}^{+}$e processo de fabricação similar, sem passivação de superfícies eficaz $[13,14]$. Steckemetz et al. [23] obtiveram eficiências da ordem de $14 \%$ em células solares em substrato $p$ e espessuras de $100 \mu \mathrm{m}$, mas com menor área, de $4 \mathrm{~cm}^{2}$. Salienta-se que os prováveis problemas de degradação das características elétricas pela interação da radiação solar com boro-oxigênio seriam evitados com as estruturas $\mathrm{p}^{+} \mathrm{nn}^{+}$ou $\mathrm{n}^{+} \mathrm{np}^{+}$analisadas neste trabalho. Os valores de eficiência obtidos neste trabalho com os dispositivos $\mathrm{n}^{+} \mathrm{np}^{+}$também foram próximos aos apresentados por Recart [24], que usou lâminas finas de silício tipo n, mas fabricou dispositivos de menor área e não considerou a barras coletoras no recobrimento da célula solar. Desta maneira, o sombreamento das células solares pela malha metálica foi reduzido, mas isto é incompatível com a indústria atual que necessita das barras coletoras para permitir a soldagem entre os dispositivos para fabricação de módulos fotovoltaicos.

\section{CONCLUSÕES}

Neste trabalho foram fabricadas e analisadas células solares $\mathrm{p}^{+} \mathrm{nn}^{+}$e $\mathrm{n}^{+} \mathrm{np}^{+}$com diferentes pastas metálicas para formar a malha de contato elétrico da face $\mathrm{p}^{+}$dopada com boro. Constatou-se que a pasta de alumínio produziu as células solares mais eficientes, em ambas as estruturas analisadas, quando comparada com a pasta de $\mathrm{Ag} / \mathrm{Al}$ e de Ag. Observou-se uma maior tensão de circuito aberto nos dispositivos com a pasta de $\mathrm{Al}$ devido à formação de uma região $\mathrm{p}^{+}$mais espessa sob a malha metálica, produzindo efeito de campo retrodifusor seletivo. Concluiu-se pelos resultados experimentais, que a pasta PV38I deve ser depositada antes do filme de $\mathrm{TiO}_{2}$, pois esta pasta não consegue perfurar o filme de forma a produzir um contato de baixa resistência elétrica.

As células solares produzidas com a pasta de $\mathrm{Al}$ na face $\mathrm{p}^{+}$e de $\mathrm{Ag}$ na face $\mathrm{n}^{+}$, atingiram eficiências de $13,4 \%$ e de $12,6 \%$ com as estruturas $n^{+} n p^{+}$e $p^{+} n n^{+}$, respectivamente. A otimização do processo térmico de queima das pastas de serigrafia combinada com a implementação de filmes passivadores de superfície são temas a serem tratados para aumentar a eficiência de conversão de energia solar em elétrica destes dispositivos.

\section{Agradecimentos}

O trabalho foi realizado no âmbito do projeto "Células Solares Bifaciais em Substratos Finos e com Região p $^{+}$Localizada”, Contrato PUCRS-CEEE nº 9942397. Os autores agradecem também o apoio do CNPq e FINEP, por meio do projeto "Desenvolvimento de Células Solares Eficientes em Lâminas de Silício Tipo n" e à equipe do NT-Solar/PUCRS pelo apoio na fabricação das células solares.

\section{REFERÊNCIAS}

I Rohatgi A. Road to cost-effective crystalline silicon photovoltaics. In: Proceedings of the 3rd World Conference on Photovoltaic Energy Conversion; 2003; Osaka, Japão. Osaka: IEEE; 2003. p. A29-A34.

2 Beaucarne G, Agostinelli G, Carnel L, Choulat P, Dekkers H, Depauw V, et al. Thin, thinner, thinnest: an evolutionary vision of crystalline Si technology. In: Proceedings of the 2 I st European Photovoltaic Solar Energy Conference; 2006; Dresden, Alemanha. Munique: WIP; 2006. p. 554-559.

$3 \mathrm{Gu} X, \mathrm{Yu} X, \mathrm{Xu}$ J, Fan R, Yang D. Towards thinner and low bowing silicon solar cells: form the boron and aluminum co-doped back surface field with thinner metallization film. Progress in Photovoltaics: Research and Applications. 20I3;2I:456-46I.

4 Mihailetchi VD, Sainova DS, Geerligs LJ, Weeber AW. 17.4\% Efficiency solar cells on large area and thin n-type silicon with screen-printed aluminum-alloyed rear emitter. In: Proceedings of the 22nd European Photovoltaic Solar Energy Conference; 2007; Milão, Itália. Munique: WIP; 2007. p. 837-840.

5 Hogan SJ. Silicon one sun, terrestrial modules. In: Partain LD. Solar cells and their applications. Nova York: John Wiley \& Sons; 1998. p. 213-221.

6 Kopecek R, Libal J. Switch from p to n. PV-Magazine, 5 juh. 2012 [acesso em 2 dez. 20 I5]. Disponível em: http:// www.pv-magazine.com/archive/articles/beitrag/switch-from-p-to-n_I00007072/50I/\#axzz2RUxJFtlL

7 Goetzberger A, Knobloch J, Voss B. Crystalline silicon solar cells. Chinchester: John Wiley \& Sons; 1994. 237 p.

8 Sopori B, Basnyat P, Devayajanam S, Shet S, Mehta V, Binns J, et al. Understanding light-induced degradation of c-Si solar cells. In: Proceedings of the 38th IEEE Photovoltaic Specialists Conference; 20I2; Austin, Texas, Estados Unidos. Piscataway: IEEE; 20I2. p. III5-II 20.

9 Geilker J, Kwapil W, Rein S. Light-induced degradation in compensated p- and n-type Czochralski silicon wafers. Journal of Applied Physics. 201 I; 109:0537।8. 
10 Moehlecke A, Zanesco I, Canizo C, Luque A. Experimental comparison between $\mathrm{p}$ and $\mathrm{n}$ bases for bifacial solar cells. In: Proceedings of the 13th European Photovoltaic Solar Energy Conference and Exhibition; 1995; Nice, França. Munique: WIP; 1995. p. I242-1245.

II Rehman A, Lee SH. Advancements in n-type base crystalline silicon solar cells and their emergence in the photovoltaic industry. The Scientific World Journal. 2013;2013:I-13.

12 Richter A, Benick J, Kalio A, Johannes S, Horteis M, Hermle M, et al. Towards industrial n-type PERT silicon solar cells: rear passivation and metallization scheme. Energy Procedia. 201 I;8:479-486.

13 Osório VC. Células solares bifaciais finas com campo retrodifusor localizado de alumínio e seletivo de boro e alumínio [tese de doutorado]. Porto Alegre: PGETEMA, Pontifícia Universidade Católica do Rio Grande do Sul; 2012.

14 Osório VC, Moehlecke A, Zanesco I. Análise do Processo de Difusão/ Queima de Pastas Metálicas e da Passivação com $\mathrm{SiO}_{2}$ em Células Solares Bifaciais Finas com região $\mathrm{p}^{+}$Localizada. In: Anais do IV Congresso Brasileiro de Energia Solar (IV CBENS) e V Conferência Latino Americana da ISES; 20I2; São Paulo. São Paulo: ABENS; 20I2. p. I-8.

I5 Kern W. Handbook of semiconductor wafer cleaning technology. New Jersey: Noyes Publications; 1998. 623 p.

16 Costa RC. Desenvolvimento de processos industriais de fabricação de células solares bifaciais em silício CZ [dissertação de mestrado]. Porto Alegre: PGETEMA, Pontifícia Universidade Católica do Rio Grande do Sul; 2009.

17 Zanesco I, Moehlecke A, Pinto JL, Ly M. Development and comparison of small and large area boron doped solar cells in n-type and p-type Cz-Si. In: Proceedings of the 38th IEEE Photovoltaic Specialist Conference; 20I2; Austin, Texas, Estados Unidos. Piscataway: IEEE; 2012. p. 2284-2288.

18 Zanesco I, Moehlecke A. Desenvolvimento de tecnologias industriais de fabricação de células solares e módulos fotovoltaicos. Rio de Janeiro: FINEP; 2012. Relatório Final Projeto FINEP.

19 Moehlecke A, Zanesco I. Desenvolvimento de células solares eficientes em lâminas de silício tipo n. Rio de Janeiro: FINEP; 2013. Relatório Técnico Projeto FINEP 2102/09.

20 Zanesco I, Moehlecke A. Processo de difusão de dopantes em lâminas de silício para a fabricação de células solares. Patente. Patente PII 2030606, BR IO 2012030606 9. 2012 Nov 30.

2I Richards BS, Cotter JE, Honsberg CB. Enhancing the surface passivation of $\mathrm{TiO}_{2}$ coated silicon wafers. Applied Physics Letters. 2002;80(7): I I 23-I I 25.

22 Caballero LJ. Contact definition in industrial silicon solar cells. In: Rugescu RD, editor. Solar energy. InTech; 20 I0. p. 375-398 [acesso em 6 jul. 2016]. Disponível em: http://www.intechopen.com/books/solarenergy/contact-definitionin-industrial-silicon-solar-cells

23 Steckemetz S, Metz A, Hezel R. Thin Cz-silicon solar cells with rear silicon nitride passivation and screen printed contacts. In: Proceedings of the 17th European Photovoltaic Solar Energy Conference; 200I; Munique, Alemanha. Munique: WIP; 200I. p. 1902-1906.

24 Recart F. Evaluación de la serigrafia como técnica de metalización para células solares eficientes [tese de doutorado]. Bilbao: Escola Superior de Engenharia de Bilbao, Universidade do País Vasco; 200 I.

Recebido em: I Set. 2016

Aceito em: 27 Dez. 2016 